\title{
Do you want to work here?
}

\section{The architects behind a new generation of laboratories believe their designs can stimulate good science. Laura Bonetta finds out how, and looks at research that may one day help to test their claims.}

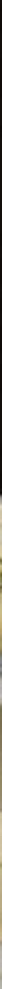

n 1992, the late virologist Jonas Salk was asked to accept an award from the American Institute of Architects for the institute he founded in La Jolla, California. In his speech, Salk told how he had visited an abbey in Assisi, Italy, while working on a polio vaccine early in his career. Although he did not go into details, he claimed that something about the architectural experience helped him to overcome difficulties in his work. In 1954, his vaccine underwent successful national trials in the United States, and eventually helped to cut the number of polio cases in the country by tens of thousands.

Are such stories one-offs, or can the physical environment really influence scientific creativity? Laboratory designers are increasingly banking on the hope that it can. Some are trying to maximize the chance encounters between scientists that spark new directions in research. Others are designing buildings intended to operate like real neighbourhoods, where workers experience a sense of community within a large building. "A lot more thought is going into the architecture of scientific buildings," says Robert McGhee, who has been resident architect with the Howard Hughes Medical Institute (HHMI) for more than 30 years.
Perhaps more importantly, at least in the long term, architects are also thinking about how they can test the claims that they make for the buildings. What does it mean to say that a building enhances creativity? Can this assertion be evaluated? A collaboration between architects and neuroscientists, established this spring, is aiming to answer such questions. Work is at an early stage, but those involved hope eventually to understand how architecture — both good and bad - affects our bodies and minds.

The current attention to good lab architecture has it roots in the Salk Institute. After his success with the polio vaccine, Salk decided to create an independent centre for biological research, and believed that architecture could play an important part in making it a success. During the late 1950s and 1960s, he worked with Louis Kahn, one of the twentieth century's most influential architects, to design an environment that was both welcoming and inspiring. "The Salk was the starting point for using the building to support the scientific community rather than just provide space," says McGhee.

Before then, labs were treated in much the same way as classroom buildings, with a corridor and often windowless rooms down each side. The Salk Institute was a departure because Kahn had a high regard for natural light and coupled it with an understanding of the functional requirements of a lab. The outer four walls of the laboratory floors are glass, creating an open and airy environment. Levels containing equipment such as centrifuges and glassware are located in floors between the labs, freeing up space for research and giving scientists room to adapt their working environment to new experiments.

\section{Pride of place}

Equally importantly, the Salk Institute is architecturally adventurous, and is regarded by many as a stunning building. It is a source of pride for those who work there, an effect that university officials are now taking into account when commissioning buildings that they hope will attract the best scientists (see Naturejobs, page 858). "Everyone who works at the Salk has an intuition that it is a special place," says Fred Gage, a neuroscientist at the institute. "The design is externally aesthetic. It is very hard to pin down, but it has an effect."

Many science buildings designed since have mimicked these design features. Take the HHMI's Janelia Farm facility, for example. The new multidisciplinary research institute 


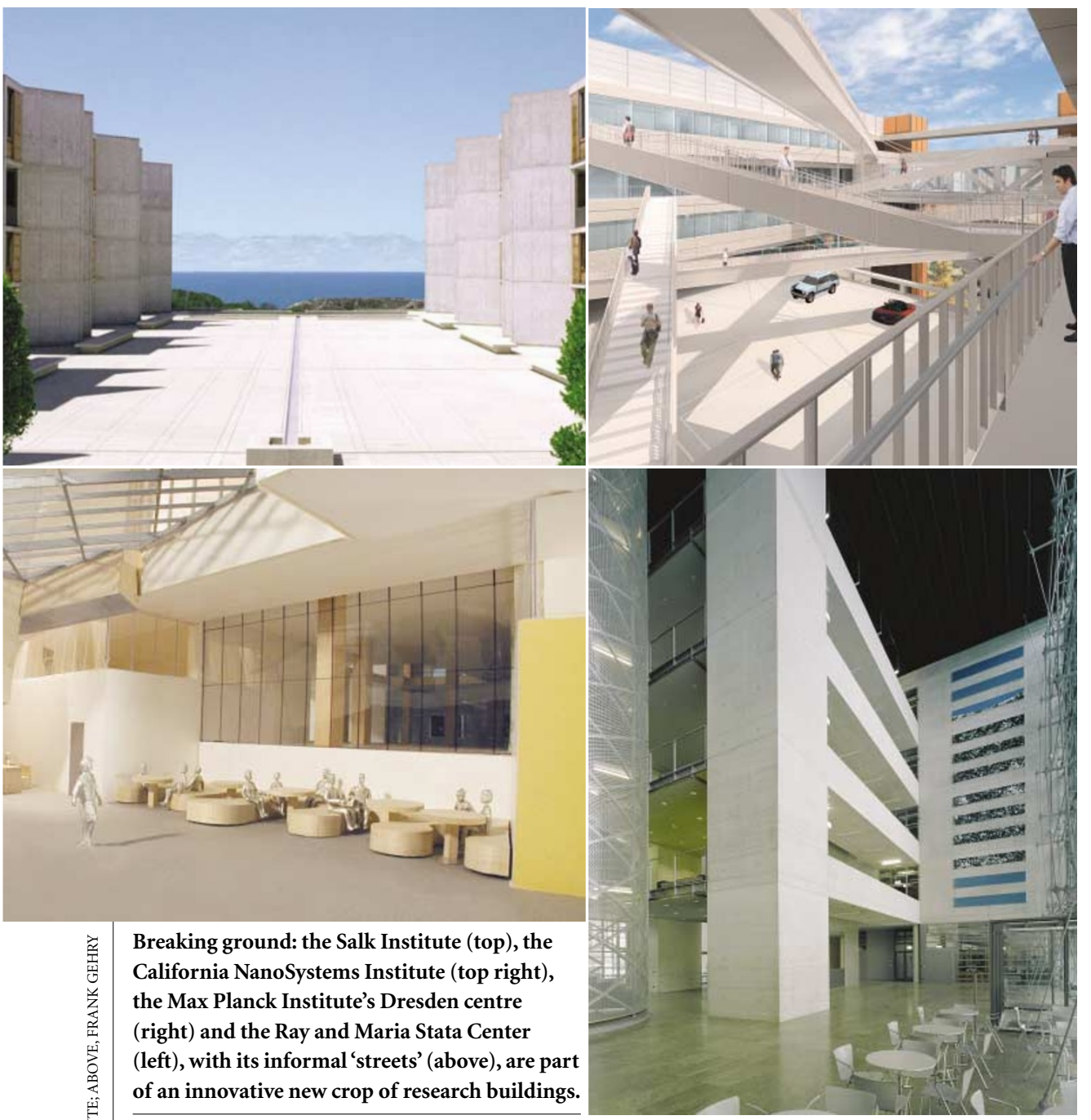

is being built into a hill on the banks of the Potomac River near Leesburg, Virginia, and is set to open in 2005. Labs at Janelia Farm are positioned along one side of a glass corridor that runs the length of the undulating building. The glazed walls and ceiling will establish a visual connection to the landscape, while also providing access to the open terraces and offices that alternate along the length of the plan opposite the labs. "It is totally different from being in a box," says McGhee, who has worked on the design with New York-based firm Rafael Viñoly Architects.

In recent years, architects have begun to pay attention to a newer concept - the need for interactive spaces in which scientists can meet and talk to each other. The trend has been fuelled partly by the rise of fields such as nanotechnology, which require scientists from different disciplines to work together. Researchers who have traditionally been scattered across a university campus are now being brought together under a single roof. "People who would not normally speak are put in an environment that stimulates interactions," says James Broach, a former acting director of the Lewis-Sigler Institute for Integrative Genomics at Princeton University, New Jersey. "The hope is that sparks will fly."
Most architects agree that vertical distance is more of a barrier than horizontal distance when it comes to researcher interaction. Atria and open staircases, which create sight lines between floors, are one solution. In the Max Planck Institute of Molecular Cell Biology and Genetics in Dresden, Germany, built in 2001, the atrium occupies the full height and width of the four-story building. Heikkinen-Komonen Architects, based in Helsinki, Finland, designed the building so that suites of labs and offices radiate from the atrium and are connected to its central staircase by concrete bridges, which the scientists call Ponte Vecchios, after the famous bridge in the Italian city of Florence. A café and dining area, overlooking a rear garden, occupy the ground floor. "The mission was to have as many chance encounters as possible," says Kai Simons, the institute's executive director.

A similar approach has been taken by Rafael Viñoly's firm in its work on the California NanoSystems Institute at the University of California, Los Angeles, which is due to be completed at the end of next year. The architects faced a particular challenge at this site, as the three levels of laboratory space will be built around an existing car park. To ensure that the parking areas do not impair movement between the labs, the design incorporates a series of zigzagging ramps that connect across and between floors.

But creating a building that increases interaction between researchers is not enough on its own. Scientists also need space and tools to help them bounce ideas off each other. With this in mind, architects design special areas, equipped with whiteboards, that should give researchers comfortable discussion space away from the bench. Deciding where to put them, however, can be tricky. "They work very well if they are in the right places," says McGhee. "But if you put them at the end of buildings, for example, they are used to get away rather than interact."

\section{Traffic management}

At the Stowers Institute for Medical Research in Kansas City, designed by Peckham Guyton Albers \& Viets, also based in Kansas City, and completed in 2000, the common rooms are in areas of high traffic - for example, where shared equipment such as imaging hardware is housed. "Labs often have the equipment across the hall," says the institute's scientific director, Robert Krumlauf. "At the Stowers you have to go to shared areas." In a similar vein, the Genentech Hall building, which opened in January 2003 at the new Mission Bay campus of the University of California, San Francisco (UCSF), uses staircase landings to foster discussions. "If you are waiting at the elevator or see someone as you are using the stairs, you can flag them down and sit to have a conversation," says Keith Yamamoto, whose genetics group moved into the building when it opened.

Food and drink also help to promote discussion, as long as the environment is right. In 1994, the Imperial Cancer Research Fund in London, now part of Cancer Research UK, added a pub to its canteen area - but staff chose to continue using other local venues, because the pub offered no added convenience or incentive for socializing, and it was removed. Other similar initiatives may prove to be more successful. At the Lewis-Sigler Institute, which opened last autumn, a critical focal point is the coffee shop, which has wireless Internet connection, in the building's atrium. "People gather there, " says Broach. "It is an opportunity to see someone you would not normally see."

But big, multidisciplinary buildings also come with problems. In a centre that employs hundreds of scientists, it is easy to feel lost. To avoid this, some architects are modelling lab layouts on real cities, with 'street' areas for interaction and 'neighbourhoods' where researchers can retreat into smaller groups. "The trend is to think about the design of a building in the way you think of cities," says Steven Wiesenthal, campus architect for UCSF.

The scientists involved in designing 
Genentech Hall, for example, borrowed the neighbourhood concept that had been perfected in labs at the UCSF's original Parnassus campus. "The research towers there were 16 stories high," says Yamamoto of the old campus. "So we renovated each floor and started the concept for neighbourhoods." Research teams were brought together in an area containing labs, offices, meeting rooms, break areas and shared equipment. The plan was to make people feel at home in a large building.

Genentech Hall, which was designed by US architects SmithGroup, with the help of Zimmer Gunsul Frasca Partnership, based in Portland, Oregon, is home to more than 70 different labs. Each 'neighbourhood', housing four or five research groups, has experiment space on the outside and offices in the middle. Research teams within a neighbourhood may share common research interests - as well as equipment, meeting rooms and eating areas - but are not necessarily from the same departments.

The Ray and Maria Stata Center at the Massachusetts Institute of Technology (MIT) in Cambridge, set to open in winter next year, will also subscribe to the neighbourhood concept. The centre's researchers, spanning a diverse range of fields, from linguistics to artificial intelligence, will occupy a series of areas, each with a two-story lounge at its centre. The building's architect, Frank Gehry, devised the scheme to provide a visual and physical connection between two levels. In addition, each neighbourhood has a central elevator core, a central staircase and some double-height labs.

\section{Proof of principle}

But will such innovative designs really bear fruit? Is the extra cost of connecting walkways justified in terms of real scientific integration? And how do we know whether natural light and open spaces get the best out of researchers? For all the good intentions of architects and the scientists who advise them, there is no proof that any of these tactics actually helps to produce better science. "Generally speaking, architects have good intuitive beliefs and some anecdotal evidence, but little beyond that," says Kevin Kampschroer, director of research for the US General Services Administration (GSA), an organization based in Washington DC that provides and maintains workspace for federal employees.

The problem that is now beginning to be considered by architects. Norman Koonce, executive vice-president of the Washingtonbased American Institute of Architects (AIA), discussed the issue in an editorial in the spring 2003 issue of the AIA's Journal of Architecture, asking: "What would it mean for architects to move beyond an intuitive and anecdotal rationale in their design? How much better could we serve our clients and the public if we understood how their brains enable perception of their physical

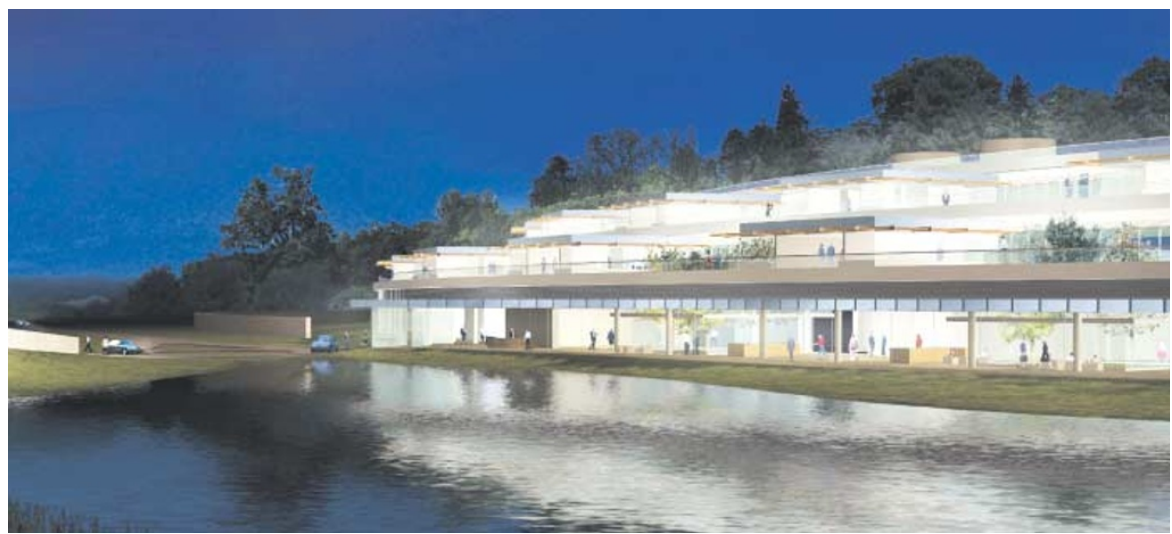

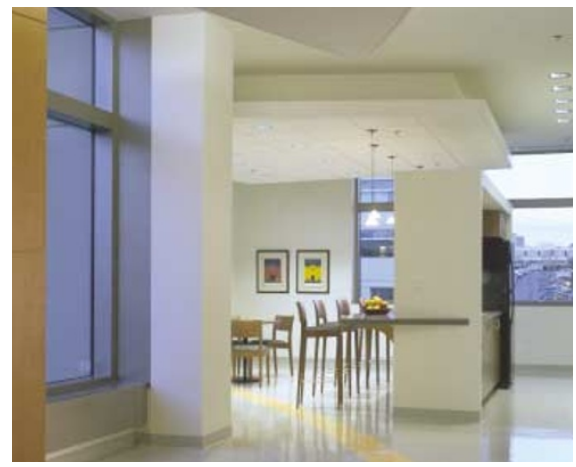

New trends: glass walls (top) and open common areas (above) are recent themes in lab design.

environment and generate physiological responses to it?"

The San-Diego-based Academy of Neuroscience for Architecture may be the place where such questions can be answered. The academy was unveiled in May, and aims to support research that bridges the gap between neuroscience and architecture. One project that will soon be under way will use functional magnetic resonance imaging to identify the brain regions that are activated when people look at historic houses, schools and churches, as opposed to contemporary ones. Other research being considered by the academy includes how lighting and acoustics can affect cognitive activity, and how the brain enables people to find their way around in complex buildings. Although such issues are not specific to lab design, they should produce results about issues such as lighting that could potentially make labs better places to work.

Little is currently known about these issues, or even about how to study them. "We have no clue how design affects the nervous system," says Gage, who has been involved in establishing the academy's research direction, and will advise its researchers when they begin work. "We don't even know what are the right questions to ask." John Eberhard, AIA director for research planning and a key figure behind the academy, believes that it will be 10-20 years before neuroscientists know enough about how the brain functions to begin to address these questions. "We are just getting started," he says.

In the meantime, projects with less lofty goals are under way. The GSA has entered a collaboration with the AIA and scientists at the US National Institutes of Health to look at the effects of stress on productivity in the office environment. Within the next month, the GSA will recruit about 200 study participants currently working in old-fashioned office environments, with features such as little natural light. The workers will spend time in three different office spaces over a period of two years, during which time their stress levels will be tracked by monitoring indicators such as heart rate and hormone concentrations.

The study will begin in the workers' existing offices, after which they will move to temporary accommodation, where they will continue to be monitored. Meanwhile, their offices will be renovated so that factors such as space, lighting, acoustics and temperature are altered. The final measurements will be taken back at the renovated offices. During this period, the workers will also be asked about how they feel about aspects of their new environments, such as lighting.

"What we are doing is unique," says Kampschroer. "There have been some studies that have looked at narrow aspects of one question or another, but nothing so comprehensive." He hopes that this study, and others planned by the GSA, will provide design guidelines based on empirical evidence. "We will be able to design for reducing stress," Kampschroer predicts.

Although researchers warn that they may not isolate a single variable that reduces stress for all workers, such projects could form the basis for a proper understanding of how workers interact with their environments. Further down the line, such studies could also contribute to a thorough evaluation of the way in which laboratories are designed, although this is still many years away. Eberhard draws comparison between architects today and medical doctors in the 1860s: "They did their best for patients but did it before anyone knew about mechanisms of disease. We think the same shift in knowledge that happened to medicine could happen to architecture."

Laura Bonetta is a freelance writer based in Bethesda, Maryland.

Academy of Neuroscience for Architecture

www.neuroscienceforarchitecture.org 